\title{
Avaliação do impacto da adição de inulina e de maçã em leite fermentado probiótico concentrado
}

\author{
Evaluation of the impact of adding inulin and apple \\ to concentrated probiotic fermented milk
}

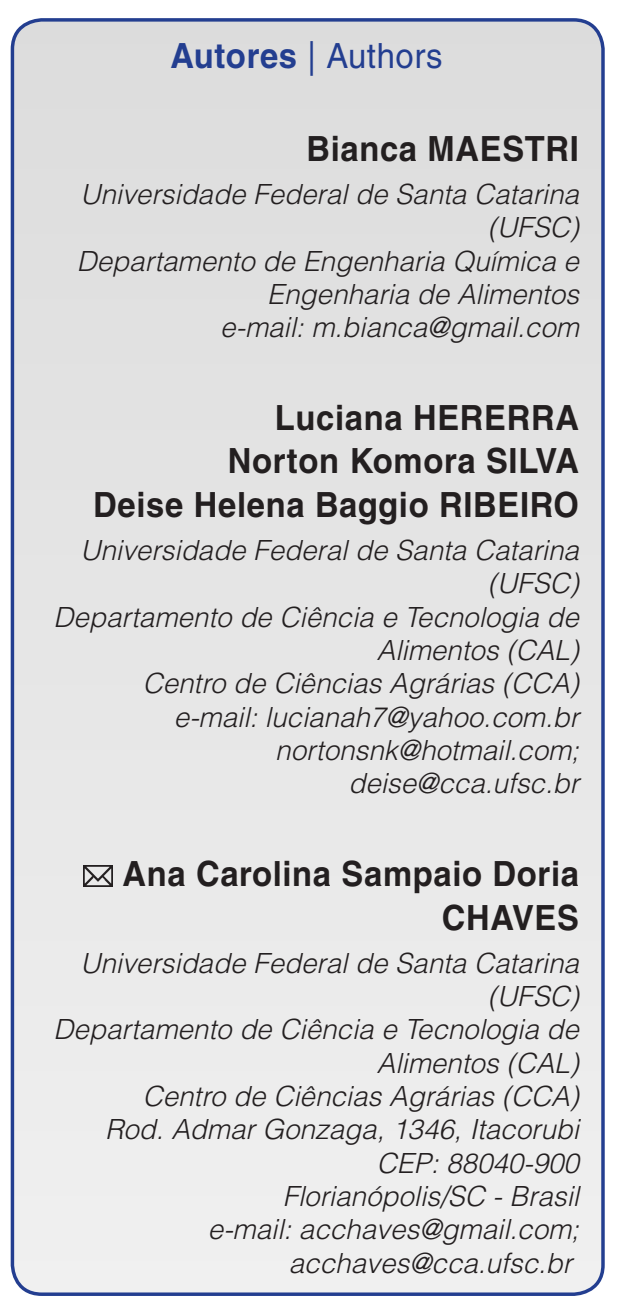

Autor Correspondente / Corresponding Author

Recebido / Received: 03/09/2013 Aprovado / Approved: 20/01/2014 Publicado / Published: mar./2014

\section{Resumo}

Neste trabalho, foi avaliado o impacto da adição de inulina na aceitação sensorial e nas características microbiológicas e físico-químicas de um leite fermentado probiótico concentrado com maçã. Foram desenvolvidas três diferentes formulações com leite UHT: integral [l]; desnatado [D]; e desnatado com $1 \%$ de inulina $(\mathrm{p} / \mathrm{p})$ [IN]. Para a fermentação, foram utilizadas as bactérias láticas: Streptococcus thermophilus, Bifidobacterium animalis Bb-12 e Lactobacillus acidophilus La-5. Para a concentração do produto (separação de soro), utilizou-se um dessorador com o produto a $4{ }^{\circ} \mathrm{C}$ por 12 horas. Com relação ao índice de aceitabilidade, não foi observada diferença significativa $(p<0,05)$ entre as formulações I, D e IN, que apresentaram, respectivamente, 82,9\%, 78,0\% e 75,1\%. As três formulações estudadas apresentaram uma boa aceitação sensorial sendo que: $98 \%$ dos provadores atribuíram notas variando de 6 (gostei ligeiramente) a 9 (gostei muitíssimo) para a formulação I; $88 \%$ para a formulação D; e $82 \%$ para a IN. Em relação à contagem de Bifidobacterium, no dia do processamento, o produto apresentou $1,4 \times 10^{8} \mathrm{UFC} / \mathrm{g}$, bem superior a $10^{6} \mathrm{UFC} / \mathrm{g}$, mínimo exigido pela legislação para que o produto possa ter alegação funcional de alimento probiótico. Após uma semana de armazenagem refrigerada, a formulação IN continha 9,6×107 UFC/g. Não foi observada diferença significativa na contagem deste probiótico durante o período de análise. O que determinou o fim da vida útil do produto foi a contagem de bolores e leveduras. Com relação aos sólidos totais e umidade, observou-se diferença significativa apenas entre a formulação $D$ e IN, a I não diferiu das demais. O teor de proteína da I foi de $5,4 \%$, mais baixo que o da $D$ e da IN, que foram de $6,2 \%$. O teor de gordura foi significativamente maior na I, igual a 3,9\%, enquanto que para a D e IN não foi observada diferença significativa. Com relação à acidez, observou-se que a da IN foi superior às demais e não foi observada diferença com relação ao teor de cinzas. Esta pesquisa demonstrou ser possível produzir leite fermentado probiótico concentrado de maçã com inulina com boa aceitação sensorial, dentro das especificações da legislação vigente.

Palavras-chave: Probiótico; Leite fermentado; Inulina; Concentrado; Maçã. 


\section{Summary}

In this study the impact of adding inulin on the sensory acceptance, microbiological and physicochemical properties of a concentrated probiotic fermented milk with apple was evaluated. Three formulations were developed: with whole UHT milk [I]; with skimmed UHT milk [D] and with skimmed UHT milk with $1 \%$ inulin $(\mathrm{w} / \mathrm{w})$ [IN]. For fermentation three lactic acid bacteria were used: Streptococcus thermophilus, Bifidobacterium animalis Bb-12 and Lactobacillus acidophilus La-5. For concentration (serum separation), the product was strained through a cheesecloth bag for 12 hours at $4^{\circ} \mathrm{C}$. The formulations were characterized according to physicochemical, microbiological and sensory analyses. Regarding the acceptability index there was no significant difference between the results $(p<0.05)$ for the formulations I, D and IN, presenting respective values of 82.9, 78.0 and $75.1 \%$. The three formulations studied showed good acceptability: $98 \%$ of the judges scored the products from 6 (like slightly) to 9 (like extremely) for formulation I, $88 \%$ for formulation D and $82 \%$ for IN. On the day of production the Bifidobacterium animalis $\mathrm{Bb}-12$ count was $1.4 \times 10^{8} \mathrm{CFU} / \mathrm{g}$, much higher than $10^{6}$ $\mathrm{CFU} / \mathrm{g}$, which is the minimum count required by Brazilian legislation for the product to make a functional claim as a probiotic food. After one week the IN formulation had a count of $9.6 \times 10^{7} \mathrm{CFU} / \mathrm{g}$, and there was no significant difference in the count of this probiotic during the period of analysis. What determined the end of the shelf life of the product was the yeast and mold count. With respect to the total solids and moisture contents, a significant difference was only observed between the formulations $\mathrm{D}$ and IN, and I did not differ from the others. The protein content of I was $5.4 \%$, lower than that of the IN and D which were $6.2 \%$. The fat content was significantly higher in I and equal to $3.9 \%$, while no significant difference was observed for D and IN. Regarding acidity, IN was superior to the others, and no difference was observed with respect to the ash contents. This research showed that was possible to produce concentrated probiotic fermented milk containing apple and inulin with good acceptability and within the specifications of current Brazilian legislation.

Key words: Probiotic; Fermented milk; Inulin; Concentrated; Apple. 


\section{Introdução}

A sociedade vive em um ritmo cada vez mais acelerado e, devido às mudanças dos hábitos alimentares e do estilo de vida, surgem diferentes problemas de saúde e doenças. Dessa forma, os alimentos saudáveis com propriedades funcionais são uma excelente alternativa para melhorar a qualidade de vida, o bem-estar e prevenir doenças. Neste contexto, observa-se um número crescente de pessoas em busca de uma alimentação saudável, de alimentos funcionais, com elevada concentração de fibras, com teores reduzidos de gorduras e de açúcares. Os alimentos são considerados funcionais quando, além de nutrir, eles promovem a melhoria da saúde do indivíduo (SAAD et al., 2013).

Uma microbiota intestinal saudável e equilibrada resulta em um desempenho normal das funções fisiológicas, assegurando melhoria da qualidade de vida. Uma colonização equilibrada, com quantidade elevada de probióticos no cólon do intestino, mantém um ambiente adverso aos patógenos que poderiam se instalar nessa região. E a adição de prebióticos aos produtos favorece a multiplicação dos probióticos nos produtos e, subsequentemente, também no cólon do intestino (OLIVEIRA et al., 2011).

A definição mais aceita de probióticos diz que eles são micro-organismos vivos que, quando administrados em quantidades adequadas, conferem benefícios à saúde do hospedeiro (FAO e WHO, 2002). Em julho de 2008, a ANVISA atualizou a lista de alimentos funcionais, que se encontra disponível eletronicamente. Segundo esta lista de alimentos funcionais, os probióticos (para conferir a alegação funcional ao alimento) devem estar presentes na porção diária (em geral de 100 gramas de produto) na faixa de $10^{8}$ a $10^{\circ}$ UFC (BRASIL, 2013).

De acordo com Brasil (2007), o MAPA determina, no Regulamento Técnico de Identidade e Qualidade de Leites Fermentados (Instrução normativa $N^{\circ} 46$, de 23/10/2007), que, quando o probiótico Bifidobacterium estiver presente em leite fermentado, ele deve ter uma contagem mínima de $10^{6} \mathrm{UFC} / g$ até o final da vida útil do produto. Para promover os efeitos probióticos, os micro-organismos devem estar viáveis e em quantidades elevadas durante toda a vida útil do produto.

A quantidade dos probióticos e a sobrevivência são influenciadas por inúmeros fatores como: a presença de outros micro-organismos no produto; a matriz do alimento no qual foi adicionado; a adição de diferentes tipos de frutas e/ou diferentes ingredientes; as condições de processamento; o tipo de embalagem usada; a barreira à passagem de oxigênio entre outros fatores (SANTOS et al., 2011).

Existem vários benefícios à saúde atribuídos ao gênero Bifidobacterium, entre eles: aumento da digestibilidade do leite, aumento do valor nutritivo (produção de vitaminas); atuação antagônica contra patógenos, evitando infecções intestinais; e modulação imunitária intestinal (VINDEROLA et al., 2000).

Os leites fermentados são excelentes veículos para consumo de probióticos, uma vez que, além de ter elevada aceitação sensorial, eles apresentam um significativo valor nutritivo (ANTUNES et al., 2007).

O iogurte concentrado além de bactérias de iogurte pode conter diferentes probióticos, sendo as mais utilizadas as dos gêneros Lactobacillus e Bifidobacterium, devido à viabilidade destes probióticos e às características sensoriais adequadas conferidas ao produto final (TAMIME et al., 2005).

A inulina, um frutoligossacarídeo não digerível comumente extraído da raiz da chicória, pode ser empregada como um substituto da gordura em produtos lácteos devido à sua capacidade de formar microcristais que resultam em uma textura cremosa, causando uma sensação sensorial semelhante à conferida pela gordura (DEBON, 2009).

A inulina é um prebiótico, pois apresenta a capacidade de aumentar o número de probióticos, devido ao fato de que no cólon do intestino ela é metabolizada seletivamente por um ou mais probióticos (MATTILASANDHOLM et al., 2002).

Segundo a ANVISA, para a inulina ser considerada um prebiótico, ela deve ser adicionada em alimentos líquidos na concentração de 1,5\% e em alimentos sólidos na de 3\% (BRASIL, 2002).

O iogurte concentrado, também conhecido como iogurte "tipo grego" ou Labneh, surgiu no Oriente Médio, onde até hoje é largamente produzido e consumido. Com a concentração do produto, ocorre um aumento da contagem das bactérias láticas, do teor de ácido lático e de sólidos totais (atingindo até 24\%), o que promove uma melhoria da conservação do produto final. No processo de produção tradicional, coloca-se o iogurte resfriado em sacos de tecido (algodão americano) até o produto atingir a concentração desejada. Esse processo é lento, pouco eficiente, de difícil higienização e tem baixo rendimento, mas ainda é utilizado em alguns países (TAMIME e ROBINSON, 2007).

$\mathrm{Na}$ literatura, observa-se que a composição de iogurte concentrado varia e, em média, o produto apresenta: de $22 \%$ a $25 \%$ de sólidos totais; de 5,5\% a $10 \%$ de gordura; até $12 \%$ de proteína; 3,0\% de lactose; $0,7 \%$ de cinzas; e pH em torno de 3,7 (KIRDAR e GUN, 2002).

Segundo Senel et al. (2011), o iogurte concentrado é um dos produtos fermentados concentrados com maior produção e consumo no mundo. No Brasil, o produto é chamado de "tipo grego" e tem se tornado cada dia mais popular. No mercado, observam-se diferentes produtos 
com variação nos sabores e apresentações. Os produtos brasileiros (começaram a ser comercializados em 2012) apresentam composição diferente da encontrada na literatura internacional. Os produtos de diferentes marcas têm concentração de proteína apenas um pouco acima da encontrada no iogurte natural, que é ao redor de $4 \%$, enquanto nos "tipo grego" varia de $4,6 \%$ a $5,1 \%$.

A maçã foi utilizada nesta pesquisa pela sua importância na economia do Estado de Santa Catarina, que é o maior produtor brasileiro, com 18.155 ha de área plantada e com 530.601 toneladas produzidas na safra de 2012/2013 (CEPA, 2013). Além disso, há um componente inovador, visto que existem raras opções de leites fermentados com maçã no mercado nacional. Esta é uma alternativa para o uso da fruta que não tem qualidade para ser comercializada diretamente como uma fruta de mesa, agregando valor a esta importante matéria-prima produzida no Estado.

Esta pesquisa teve como objetivo desenvolver e avaliar diferentes formulações de leites fermentados probióticos (com Bifidobacterium animalis e Lactobacillus acidophilus) concentrados com adição de maçã. Foi avaliado o impacto da adição de inulina como substituto de gordura no produto por meio da determinação das características microbiológicas, físico-químicas e sensoriais do produto.

\section{Material e métodos}

\subsection{Processamento do leite fermentado concentrado probiótico e do preparado de maçã}

Nas diferentes formulações do produto estudado neste trabalho, foram utilizados: leite esterilizado UHT integral e desnatado (marca Elegê); leite em pó desnatado (marca La Sereníssima), açúcar light (mistura comercial de sacarose e sucralose, da marca União) e maçãs da variedade Fuji. Todos os produtos foram adquiridos no mercado local, em Florianópolis, SC.

O fermento utilizado foi uma cultura lática ABT-4 mista probiótica liofilizada tipo DVS (Chr Hansen, Dinamarca), que contém: Streptococcus thermophilus, Bifidobacterium animalis Bb-12 e Lactobacillus acidophilus La-5. O fermento foi preparado segundo indicações do fabricante. O conteúdo de um pacote DVS de $50 \mathrm{U}$ foi misturado com $50 \mathrm{ml}$ de leite UHT, dissolvido por dois minutos sob agitação, dividido em tubos plásticos e congelado a $-18{ }^{\circ} \mathrm{C}$ até o momento de uso. Uma hora antes da inoculação, o fermento foi descongelado e adicionado às diferentes formulações na proporção de $5 \%$ (para o produto final atingir uma concentração mínima de $\left.10^{9} \mathrm{UFC} / \mathrm{mL}\right)$.

A inulina utilizada nesta pesquisa foi da Orafti (empresa Clariant). Antes de ser adicionada ao leite, a inulina em pó (para atingir a concentração de 1\% p/p em relação ao leite) foi dissolvida em leite UHT e esterilizada em autoclave a $121^{\circ} \mathrm{C}$ por 15 minutos.

As diferentes formulações foram processadas na Usina de Processamento de Alimentos do Departamento de Ciência e Tecnologia de Alimentos (CAL), no Centro de Ciências Agrárias (CCA) da Universidade Federal de Santa Catarina (UFSC). As diferentes análises foram realizadas nos laboratórios de microbiologia e de bromatologia deste departamento.

Para avaliar o impacto da adição de inulina, foram desenvolvidas três diferentes formulações. Em todas elas adicionou-se $2 \%$ de leite desnatado em pó (p/p) em relação ao leite UHT (integral ou desnatado) com o objetivo de aumentar o teor de proteína do produto final para obter um gel firme sem sinérese. Na Formulação I, foi utilizado leite integral; na Formulação D, utilizou-se leite desnatado; na Formulação IN, o leite desnatado e $1 \%$ de inulina $(\mathrm{p} / \mathrm{p})$ para avaliar o seu efeito como um substituto de gordura.

Depois da mistura do leite fluido com o leite em pó, foi realizada a pasteurização $\left(95^{\circ} \mathrm{C}\right.$ por 5 minutos $)$ das diferentes formulações e, subsequentemente, o resfriamento até $43^{\circ} \mathrm{C}$. Procedeu-se à inoculação com $5 \%$ do fermento probiótico, e o produto foi incubado em uma câmara BOD a $43^{\circ} \mathrm{C}$ até atingir o pH final de 4,6 , quando foi resfriado a $4{ }^{\circ} \mathrm{C}$ por 12 horas. Depois do resfriamento, o gel foi quebrado e transferido para um dessorador para a separação do soro por 12 horas sob refrigeração. Durante a fermentação foram realizadas medidas de $\mathrm{pH}$ a cada 30 minutos para construção de uma curva de fermentação para avaliar o impacto da inulina nesta etapa do processo.

Para a elaboração do preparado de maçã (variedade Fuji), as frutas foram lavadas em água corrente e sanitizadas por imersão em solução de hipoclorito de sódio 200 ppm por 15 minutos. As maçãs foram descascadas, cortadas, branqueadas em água em ebulição por 3 minutos e, subsequentemente, desintegradas em liquidificador industrial. Adicionou-se à maçã desintegrada, em relação à massa de fruta, 30\% $(\mathrm{p} / \mathrm{p})$ de uma mistura comercial de sacarose e sucralose (marca União); $0,5 \%$ de ácido cítrico ( $p / p)$ e $1 \%$ de pectina cítrica $(\mathrm{p} / \mathrm{p})$. A mistura foi concentrada até atingir $40^{\circ}$ Brix, embalada em recipientes de vidro previamente esterilizados, fechados hermeticamente e armazenados a $5{ }^{\circ} \mathrm{C}$ até o momento da utilização.

O produto final (leite fermentado concentrado de maçã) foi preparado misturando-se $25 \%$ do preparado de maçã (p/p) com $75 \%$ de leite fermentado concentrado. As diferentes formulações foram colocadas em embalagens plásticas tampadas (com as quantidades necessárias para cada uma das análises) e mantidas a $4{ }^{\circ} \mathrm{C}$ até a 
Avaliação do impacto da adição de inulina e de maçã em leite fermentado probiótico concentrado MAESTRI, B. et al.

realização das análises (físico-químicas, microbiológicas e sensoriais) para caracterizá-las.

\subsection{Análises microbiológicas}

A análise microbiológica do produto foi realizada em duplicata nos dias 0 e 7 de armazenagem a 4 ${ }^{\circ} \mathrm{C}$. Logo após o processamento (no dia zero), antes da análise sensorial, foram realizadas as análises microbiológicas para a contagem de bolores e leveduras, de coliformes totais e de coliformes termotolerantes, com o objetivo de avaliar as condições higiênico-sanitárias do processamento (SILVA et al., 2010).

A contagem de Streptococcus thermophilus e de Lactobacillus acidophilus foi realizada segundo APHA (2004). A contagem de Bifidobacterium foi realizada em MRS com glicose, adicionado de $5 \mathrm{ml}$ da solução de Dicloxacillina, $10 \mathrm{ml}$ de solução de LiCl e $5 \mathrm{ml}$ de solução de $\mathrm{CyHCl}$ por litro de meio de cultura. As placas foram incubadas a $37^{\circ} \mathrm{C}$ por $72 \mathrm{~h}$ em anaerobiose (CHR HANSEN, 2007).

\subsection{Análises físico-químicas}

As análises físico-químicas para a caracterização do produto seguiram as metodologias propostas pelo Instituto Adolfo Lutz (IAL, 2008). Foram realizadas as seguintes análises: pH (leitura direta em potenciômetro); acidez total titulável (\% de ácido lático); teor de proteína (Método de Kjeldahl); lipídios (Soxhlet); umidade (estufa a $105^{\circ} \mathrm{C}$ ) e cinzas.

\subsection{Análise sensorial}

Para avaliar a aceitação sensorial das diferentes formulações, foram utilizados 50 provadores não treinados recrutados entre alunos, professores e funcionários da
UFSC. Utilizou-se uma escala hedônica estruturada de nove pontos, com notas variando de 9 (gostei muitíssimo) a 1 (desgostei muitíssimo). Os provadores receberam as amostras de forma monádica, em copos plásticos transparentes descartáveis com tampas contendo $25 \mathrm{~g}$ do produto a $8^{\circ} \mathrm{C}$. As amostras foram codificadas com números aleatórios de três dígitos e servidas com um copo de água. Para avaliar a aceitação sensorial, foi seguida a metodologia proposta por Meilgaard et al. (2006) e o índice de aceitação foi calculado segundo Teixeira et al. (1987).

\subsection{Análise estatística}

O experimento foi repetido e os resultados apresentados são a média destes dois experimentos. Os resultados das análises microbiológicas, sensorial e físico-químicas foram submetidos à análise de variância (ANOVA) e ao Teste de Tukey $(p<0,05)$ para comparação das médias. Os cálculos foram realizados com auxílio dos programas Statistica ${ }^{\circledR}$ e Excel ${ }^{\circledR} 2007$ (Windows).

\section{Resultados e discussão}

\subsection{Influência da inulina no tempo de fermentação do leite}

O tempo de fermentação das diferentes formulações variou entre 5 e 6 horas, sendo que o final da fermentação foi determinado quando as amostras atingiram $\mathrm{pH}$ de 4,6 . Este resultado demonstrou que a adição de inulina não influenciou o tempo de fermentação, uma vez que as formulações I e IN tiveram comportamentos similares, como pode ser observado na Figura 1.

Segundo Tamime e Robison (2007), o tempo de fermentação de iogurte varia de 2,5 a 5 horas e isto ocorre devido às combinações e quantidades de bactérias

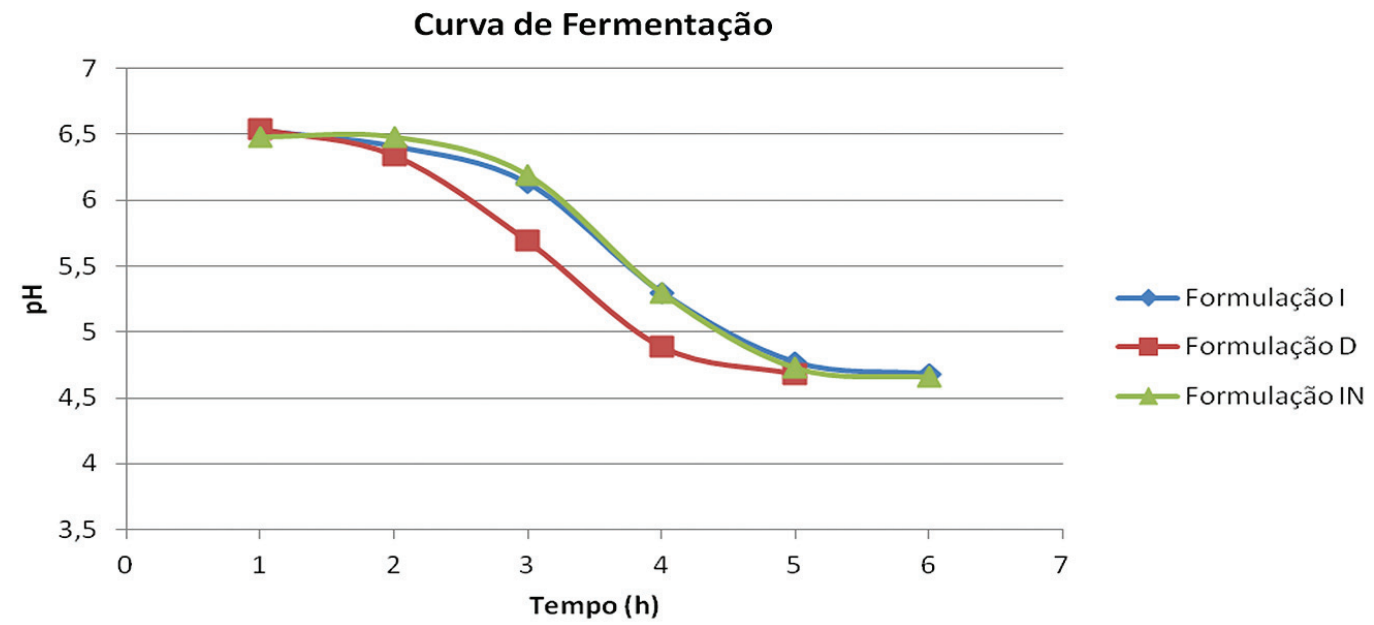

Figura 1. Curva de decréscimo do pH durante a fermentação das diferentes formulações. 
láticas adicionadas. Neste experimento, foi observado um tempo de fermentação ligeiramente superior ao observado na produção de iogurte, o que poderia ser explicado pela ausência de Lactobacillus bulgaricus, que se multiplica em uma associação positiva com o $S$. thermophilus, acelerando o processo de fermentação (MUNDIM, 2008).

O tempo de fermentação nesta pesquisa foi menor do que os observados por Dave e Shah (1997), que utilizaram a mesma combinação de bactérias láticas e observaram que esta etapa demorou de 6,5 a 11 horas. Atualmente, os fermentos probióticos disponíveis no mercado fermentam o leite rapidamente como pode ser observado nesta pesquisa.

\subsection{Avaliação das diferentes formulações por meio das análises microbiológicas}

Logo após o processamento, as amostras foram submetidas às análises microbiológicas (quantificação de coliformes totais, de coliformes termotolerantes e contagem de bolores e leveduras), nas quais foram observados resultados negativos para os contaminantes pesquisados ou a contagem encontrava-se dentro das especificações estipuladas pela legislação vigente. Este resultado evidenciou que as diferentes formulações foram processadas em condições higiênico-sanitárias adequadas e todas se encontravam aptas para o consumo no momento da análise sensorial.

Como se observa na Tabela 1, as amostras IN apresentaram contagem suficiente de Bifidobacterium animalis para promover efeitos benéficos à saúde do consumidor e, portanto, este produto poderia ter uma alegação funcional de probiótico de acordo com a legislação brasileira vigente. Depois de uma semana de armazenagem refrigerada, foi observada uma pequena redução do número de células viáveis de Bifidobacterium, que pode ser devido à permeação de oxigênio através da embalagem ou à acidificação do produto (FERREIRA e TESHIMA, 2000).

O aumento da contagem de bolores e leveduras foi o que determinou o final da vida útil do produto, pois, com uma semana, o produto atingiu a contagem de $2 \times 10^{2}$ UFC/g, que é o máximo permitido pela legislação vigente; acima deste valor o produto encontra-se impróprio

Tabela 1. Resultados das análises microbiológicas do leite fermentado concentrado com inulina.

\begin{tabular}{ccc} 
Análise & Dia 0 & Dia 7 \\
Coliformes totais (NMP) & 0 & 0 \\
Bifidobacterium animalis (UFC/g) & $1,4 \times 10^{8}$ & $9,6 \times 10^{7}$ \\
Streptococcus thermophilus e & $5 \times 10^{9}$ & $2,6 \times 10^{9}$ \\
Lactobacillus acidophillus (UFC/g) & $10^{2}$ & $2 \times 10^{2}$ \\
Bolores e leveduras (UFC/g) & $10^{2}$ & \\
\hline
\end{tabular}

para o consumo. Por esta razão, a avaliação de vida útil do produto foi realizada somente até o sétimo dia, apesar de a contagem de bactérias láticas totais e de Bifidobacterium animalis ainda estarem elevadas, bem acima do mínimo exigido pela legislação brasileira. Esta contaminação por bolores e leveduras provavelmente é devido à adição do preparado de maçã sem conservantes químicos ou à etapa de concentração do leite fermentado com auxílio de um dessorador.

O tempo de vida útil de produtos similares, como o iogurte concentrado obtido de forma tradicional (nos quais se utilizam sacos de algodão) também é curto. Yamani e Abu-Jaber (1994) observaram que a vida útil deste produto variou de 7 a 10 dias; e Nsabimana et al. (2005) observaram uma vida útil de cerca de duas semanas. Devido à curta vida útil do produto obtido pelo método tradicional, observa-se uma ampla utilização de conservantes como benzoatos e sorbatos para o controle da multiplicação de micro-organismos deteriorantes nestes produtos (MIHYAR et al., 1999).

No Brasil, só é permitida a adição de conservantes nos preparados de frutas naturais ou nos preparados de aromatizantes/saborizantes artificiais adicionados aos leites fermentados, não sendo permitida a adição de conservantes diretamente nos leites fermentados (BRASIL, 2007). Portanto, considerou-se que o produto elaborado nesta pesquisa obteve uma vida útil compatível com a observada na literatura por outros pesquisadores em produtos similares.

A utilização de dessoradores para a separação do soro não é eficiente devido ao tempo prolongado, que pode propiciar a contaminação do produto. Esta etapa poderia ser substituída por concentração em centrífugas ou com membranas, que, além de serem técnicas mais rápidas e eficientes, são também mais higiênicas e poderiam contribuir para um aumento da vida útil do produto final.

\subsection{Avaliação das diferentes formulações por meio das análises físico-químicas}

Os resultados das análises físico-químicas são apresentados na Tabela 2 (média e desvio padrão).

Segundo Tamime e Robison (2007), diferentes pesquisadores encontraram valores de sólidos totais em produtos similares variando de $24,1 \%$ a $23 \%$. Os resultados encontrados nesta pesquisa variaram de $19,8 \%$ a 23,5\%. Os valores encontrados nas formulações $\mathrm{D}$ e IN foram abaixo da média encontrada na literatura e o da IN estava dentro da faixa esperada. A formulação D foi a que apresentou o menor valor, provavelmente, devido ao fato de ter sido utilizado leite desnatado. O valor máximo foi observado na formulação com inulina, devido ao maior conteúdo de sólidos adicionados ao 
Avaliação do impacto da adição de inulina e de maçã em leite fermentado probiótico concentrado MAESTRI, B. et al.

Tabela 2. Resultado das análises físico-químicas das diferentes formulações.

\begin{tabular}{cccc}
\hline Análises & Formulação I & Formulação D & Formulação IN \\
\hline Sólidos totais (\%) & $21,8^{\mathrm{ba}} \pm 0,2$ & $19,8^{\mathrm{a}} \pm 0,02$ & $23,5^{\mathrm{b}} \pm 0,09$ \\
Proteína (\%) & $5,4^{\mathrm{a}} \pm 0,1$ & $6,2^{\mathrm{b}} \pm 0,05$ & $6,2^{\mathrm{b}} \pm 0,05$ \\
Gordura (\%) & $3,9^{\mathrm{a}} \pm 0,5$ & $0,16^{\mathrm{b}} \pm 0,02$ & $0,33^{\mathrm{b}} \pm 0,01$ \\
Acidez titulável ( $\left.{ }^{\circ} \mathrm{D}\right)$ & $131,0^{\mathrm{a}} \pm 1,4$ & $132,5^{\mathrm{a}} \pm 2,1$ & $155,5^{\mathrm{b}} \pm 0,7$ \\
Ácido lático (\%) & $1,3^{\mathrm{a}} \pm 0,0$ & $1,3^{\mathrm{a}} \pm 0,02$ & $1,5^{\mathrm{b}} \pm 0,01$ \\
Cinzas (\%) & $0,6^{\mathrm{a}} \pm 0,0$ & $0,59^{\mathrm{a}} \pm 0,1$ & $0,62^{\mathrm{a}} \pm 0,03$ \\
Umidade (\%) & $78,2^{\mathrm{ba}} \pm 0,2$ & $80,2^{\mathrm{a}} \pm 0,0$ & $76,5^{\mathrm{b}} \pm 0,09$ \\
\hline
\end{tabular}

As letras diferentes na mesma linha indicam que as amostras apresentam diferença significativa $(p<0,05)$. Formulação I: elaborada com leite integral; Formulação D: elaborada com leite desnatado; Formulação IN: elaborada com leite desnatado e 1\% de inulina.

leite. O conteúdo de sólidos totais reportado por Yazici e Akgun (2003) para iogurte concentrado foi igual a 21,8\% com $0,75 \%$ de substituto de gordura e igual a $20,0 \%$ para a formulação sem substituto.

O teor de proteína das diferentes formulações variou de $5,4 \%$ a $6,2 \%$, todas elas atenderam ao estabelecido pela legislação brasileira, que exige um mínimo de 2,9\% (BRASIL, 2007). Porém, na literatura, em produtos concentrados em geral, observa-se um teor de proteína bem superior. Em iogurte concentrado com substituto de gordura, foi observado 12,3\% de proteína (YAZICI e AKGUN, 2003).

Em relação ao teor de gordura, a legislação brasileira estabelece um máximo de 0,5\% para classificar o produto como desnatado, dessa forma, as formulações D (com $0,16 \%$ de gordura) e IN (com 0,33\%), que foram elaboradas com leite desnatado, poderiam ser classificadas como desnatadas.

A acidez das formulações variou de 1,3\% a 1,5\%, atendendo ao estabelecido pela legislação, que prevê que a acidez fique na faixa de 0,6\% a 2,0\%. A formulação IN apresentou um valor significativamente superior ( $\mathrm{p}<$ $0,05)$ em relação às demais.

A Instrução normativa $n^{\circ} 46$, de 2007, não faz menção ao teor de cinzas. As três formulações caracterizadas não apresentaram diferença significativa quanto ao teor de cinzas, que variou de 0,59\% a 0,62\%. Yazici e Akgun (2003) observaram valores de cinzas um pouco acima, variando de $0,66 \%$ a $0,72 \%$ para iogurte concentrado sem e com adição de substituto de gordura, respectivamente.

\subsection{Avaliação das diferentes formulações por meio de análises sensoriais}

O índice de aceitação das formulações I, D e IN foram respectivamente $83 \%, 78 \%$ e $75 \%$, o que reflete que todas elas apresentaram uma boa aceitação por parte dos provadores, uma vez que o produto é considerado sensorialmente aceito quando tem um índice de aceitabilidade igual ou superior a 70\% (TEIXEIRA et al., 1987). Não se observou diferença significativa ( $p<$
$0,05)$ entre as diferentes formulações processadas nesta pesquisa, mas, em geral, sabe-se que a gordura do leite afeta favoravelmente a qualidade de derivados de leites, incluindo os derivados de leites fermentados, conferindo melhor textura e sabor agradável (MUNDIM, 2008).

As três formulações estudadas nesta pesquisa apresentaram uma boa aceitação sensorial, sendo que: $98 \%$ dos provadores atribuíram notas variando de 6 (gostei ligeiramente) a 9 (gostei muitíssimo) para a formulação I; 88\% para a formulação D; e 82\% para a IN.

Em relação à aceitabilidade das amostras preparadas com leite desnatado com ou sem inulina, Robinson (1995), em suas pesquisas, também não observou impacto positivo da adição de inulina na textura de iogurte em comparação ao produto controle.

\section{Conclusão}

Esta pesquisa evidenciou ser possível elaborar um leite fermentado probiótico concentrado de maçã com adição de inulina, como substituto da gordura láctea, com boa aceitação sensorial e com características físicoquímicas e microbiológicas compatíveis com a legislação brasileira.

A curta vida útil do produto de sete dias sob refrigeração deve-se à contagem de bolores e leveduras estar acima da máxima permitida. Até sete dias de armazenagem, a contagem de Bifidobacterium de $9,7 \times 10^{7}$ UFC/g é elevada o suficiente para conferir alegação funcional ao produto como leite fermentado probiótico.

\section{Agradecimentos}

À empresa Chr Hansen pela doação da cultura lática mista probiótica DVS ABT-4 e à empresa Clariant pela doação de inulina (Orafti).

\section{Referências}

AMERICAN PUBLIC HEALTH ASSOCIATION - APHA. Standard Methods for the Examination of Dairy Products. 17. ed. Washington: APHA, 2004. 570 p. 
Avaliação do impacto da adição de inulina e de maçã em leite fermentado probiótico concentrado MAESTRI, B. et al.

ANTUNES, A. E. C.; SILVA, E. R. A.; MARASCA, E. T. G.; MORENO, I.; LERAYER, A. L. S. Desenvolvimento de buttermilk probiótico. Ciência Tecnologia de Alimentos, Campinas, v. 27, n. 1, p. 83-90, jan./mar. 2007. http://dx.doi.org/10.1590/S010120612007000100015

BRASIL. Ministério da Saúde. Agência Nacional de Vigilância Sanitária. Resolução n 2, de 07 de janeiro de 2002. Regulamento técnico de substâncias bioativas e probióticos isolados com alegação de propriedade funcional ou de saúde. Diário Oficial da República Federativa do Brasil, Brasília, 09 jan. 2002. Seção 1, p. 192-193.

BRASIL. Ministério da Agricultura, Pecuária e Abastecimento. Instrução normativa n 46, de 23 de outubro de 2007. Adota o Regulamento Técnico de Identidade e Qualidade de Leites Fermentados. Diário Oficial da República Federativa do Brasil, Brasília, 24 out. 2007

BRASIL. Ministério da Saúde. Agência Nacional de Vigilância Sanitária. Alegações de propriedades funcionais aprovadas. Brasília: Ministério da Saúde. Disponivel em: <http://portal. anvisa.gov.br/wps/content/Anvisa+Portal/Anvisa/Inicio/ Alimentos/Assuntos+de+Interesse/Alimentos+Com+Alegaco es+de+Propriedades+Funcionais +e+ou+de+Saude/Alegaco es+de+propriedade+funcional+aprovadas $>$. Acesso em: 25 out. 2013.

CENTRO DE SOCIOECONOMIA E PLANEJAMENTO AGRÍCOLA - CEPA. Dados e Informações. Florianópolis, 2013. Disponível em: <http://cepa.epagri.sc.gov.br/>. Acesso em: 25 out. 2013.

CHR HANSEN. Bifidobacteria Enumeration ABC Alternative Method for Enumeration of Bifidobacteria in Fermented Milk Products. Denmark: Chr. Hansen A/S, 2007. (Technical Bulletin, n. 12)

DAVE, R. I.; SHAH, N. P. Viability of yoghurt and probiotic in yoghurt made from commercial starter cultures. International Dairy Journal, Barking, v. 7, n. 1, p. 31-41, 1997.

DEBON, J. Emprego da Microfiltração Tangencial na Obtenção de Leite Fermentado Prebiótico. 2009. 120 f. Dissertação (Mestrado em Engenharia de Alimentos)-Universidade Federal de Santa Catarina, Florianópolis, 2009.

INSTITUTO ADOLFO LUTZ - IAL. Normas Analíticas do Instituto Adolfo Lutz: Métodos Químicos e Físicos para Análise de Alimentos. 4. ed. São Paulo: IAL, 2008. 1020 p.

FOOD AND AGRICULTURE ORGANIZATION OF THE UNITED NATIONS - FAO; WORLD HEALTH ORGANIZATION - WHO. Guidelines for the Evaluation of Probiotics in Food. Canada: FAO/WHO, 2002.

FERREIRA, C. L. L. F.; TESHIMA, E. Prebióticos. Biotecnologia, Ciência \& Desenvolvimento, Brasília, n. 16, p. 22-25, 2000.
KIRDAR, S.; GUN, I. Microbiological, chemical and physical properties of strained yoghurt consumed in Burdur market. Gida, Local de publicação da revista, v. 27, n. 1, p. 59-64, 2002.

MATTILA-SANDHOLM, T.; MYLLARINEN, P.; CRITTENDEN, R.; MOGENSEN, G.; FONDEN, R.; SAARELA, M. Technological challenges for future probiotic foods. International Dairy Journal, Barking, v. 12, n. 2/3, p. 173-182, 2002.

MEILGAARD, M.; CIVILLE, G. V.; CARR, B. T. Sensory Evaluation Techniques. 4. ed. Boca Raton: Taylor \& Francis, 2006. 125 p. http://dx.doi.org/10.1201/b16452

MIHYAR, G. F.; YOUSIF, A. K.; YAMANI, M. I. Determination of benzoic and sorbic acids in labneh by high-performance liquid chromatography. Journal Food Composition and Analysis, London, v. 12, n. 1, p. 53-61, 1999. http://dx.doi.org/10.1006/ jfca.1998.0804

MUNDIM, S. A. P. Elaboração de logurte Funcional com Leite de Cabra, Saborizado com Frutos do Cerrado e Suplementado com Inulina. 2008. 115 f. Dissertação (Mestrado em Ciências)-Universidade Federal do Rio de Janeiro, Rio de Janeiro, 2008.

NSABIMANA, C.; JIANG, B.; KOSSAH, R. Manufacturing, properties and shelf life of labneh: a review. International Journal of Dairy Technology, Barking, v. 58, n. 3, p. 129-137, 2005.

OLIVEIRA, R. P. S.; PEREGO, P.; OLIVEIRA, M. N; CONVERTI, A. Growth and survival of mixed probiotics in nonfat fermented milk: the effect of inulin. Chemical Engineering Transactions, Italy, v. 24, p. 457-462, 2011.

ROBINSON, R. K. The potential of inulin as a functional ingredient. Brazilian Food Journal, Campinas, v. 97, n. 4, p. 30-32, 1995.

SAAD, N.; DELATTRE, C.; URDACI, M.; SCHMITTER, J. M.; BRESSOLLIER, P. An overview of the last advances in probiotic and prebiotic field. LWT Food Science and Technology, London, v. 50, n. 1, p. 1-16, 2013. http://dx.doi.org/10.1016/j. Iwt.2012.05.014

SANTOS, A. P. D.; PEREGO, P.; CONVERTI, A.; OLIVEIRA, M. N. Influence of food matrices on probiotic viability: a review focusing on the fruity bases. Trends in Food Science \& Technology, Cambridge, v. 22, p. 377-385, 2011

SENEL, E.; ATAMER, M.; GÜRSOY, A.; ÖZTEKIN, F. Changes in some properties of strained (Süzme) goat's yoghurt during storage. Small Ruminant Research, Amsterdam, v. 99, n. 2-3, p.171-177, 2011. http://dx.doi.org/10.1016/j. smallrumres.2011.03.042

SILVA, N.; JUNQUEIRA, V. C. A.; SILVEIRA, N. F. A. Manual de métodos de análise microbiológica de alimentos e água. 4. ed. São Paulo: Livraria Varela, 2010. 
Avaliação do impacto da adição de inulina e de maçã em leite fermentado probiótico concentrado MAESTRI, B. et al.

TAMIME A. Y.; SAARELA, M.; SØNDERGAARD, A. K.; MISTRY, V. V.; SHAH, N. P. Production and maintenance of viability of probiotic micro-organisms in dairy products. In: TAMIME, A. Y. Probiotic dairy products. Oxford: Blackwell, 2005. p. 39-72.

TAMIME, A. Y.; ROBINSON, R. K. Yoghurt science and technology. 3. ed. Inglaterra: Woodhead Publishing Limited: CRC Press LLC, 2007. p. 791.

TEIXEIRA, E.; MEINERT, E. M.; BARBETTA, P. A. Análise sensorial de alimentos. Florianópolis: UFSC, 1987. p. 180.

VINDEROLA, C. G.; PROSELLO, W.; GHIBERTO, D.; REINHEIMER, J. A. Viability of probiotic (Bifidobacterium,
Lactobacillus acidophilus and Lactobacillus casei) and nonprobiotic microbiota in Argentinian Fresco Cheese. Journal Dairy Science, Barking, v. 83, n. 9, p. 1905-1911, 2000.

YAMANI, M. I.; ABU-JABER, M. M. Yeast flora of labaneh produced by in-bag straining of cow milk set yogurt. Journal Dairy Science, Barking, v. 77, n. 12, p. 3558-3564, 1994.

YAZICI, F.; AKGUN, A. Effect of some protein based fat replacers on physical, chemical, textural and sensory properties of strained yoghurt. Journal of Food Engineering, Essex, v. 62, n. 3, p. 245-254, 2003. 